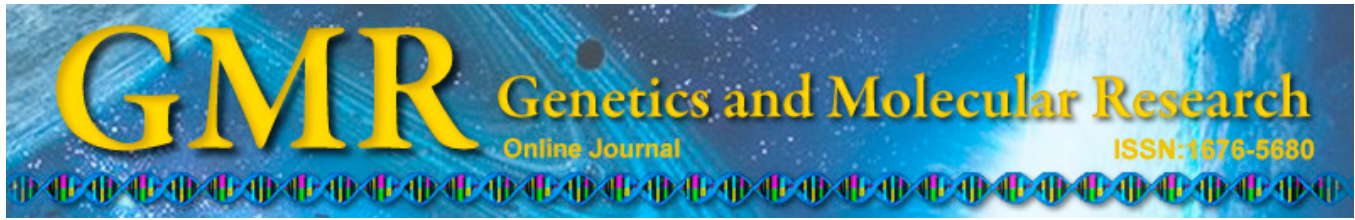

\title{
Detection of a novel single nucleotide polymorphism and imprinted status analysis of the Ras protein-specific guanine nucleotide- releasing factor 1 gene in domestic pigs
}

\author{
Y.Y. Ding ${ }^{1 *}$, L.Y. Liu ${ }^{2 *}$, J. Zhou ${ }^{2}$, X.D. Zhang ${ }^{1}$, L. Huang ${ }^{1}$, S.J. Zhang ${ }^{2}$ \\ and Z.J. Yin ${ }^{1}$ \\ ${ }^{1}$ Anhui Provincial Laboratory for Local Livestock and Poultry Genetic \\ Resource Conservation and Bio-Breeding, Department of Animal Science, \\ College of Animal Science and Technology, Anhui Agricultural University, \\ Hefei City, Anhui, China \\ ${ }^{2}$ Department of Veterinary, College of Animal Science and Technology, \\ Anhui Agricultural University, Hefei City, Anhui, China \\ *These authors contributed equally to this study. \\ Corresponding authors: Z.J. Yin / J. Zhou \\ E-mail: yinzongjun@ahau.edu.cn / zhoujie@ahau.edu.cn
}

Genet. Mol. Res. 13 (4): 10574-10581 (2014)

Received November 26, 2013

Accepted March 7, 2014

Published December 12, 2014

DOI http://dx.doi.org/10.4238/2014.December.12.20

\begin{abstract}
The aim of this study was to determine the imprinting status of the Ras protein-specific guanine nucleotide-releasing factor 1 (Rasgrf1) gene in domestic pigs. In this study, a 228-bp partial sequence located in exon 14 and a 193-bp partial sequence located in exon 1 of the Rasgrfl gene in domestic pigs were obtained. A novel single nucleotide polymorphism, a G/A transition, was identified in Rasgrf1 exon 14, and then the reciprocal Berkshire $\mathrm{x}$ Wannan black F1 hybrid model and the reverse transcription-polymerase chain reaction-restriction fragment length polymorphism method were used to detect the imprinting status of the porcine Rasgrfl gene at the 1-day-old developmental stage.
\end{abstract}


Imprinting analysis showed that, compared to the imprinted expression of the Rasgrfl gene in mouse and rat, a variable imprinting status was observed in domestic pigs. In principle, the porcine Rasgrfl gene was maternally expressed in the liver and small intestine, paternally expressed in the lung, and biallelically expressed in brain, heart, spleen, kidney, stomach, pancreas, fat, testis, ovary, longissimus dorsi, and pituitary tissues. In conclusion, our results indicated that the RasgrfI gene shows both species- and tissue-specific variation in imprinted expression.

Key words: Domestic pigs; Single nucleotide polymorphism; Rasgrf1; Imprinting analysis

\section{INTRODUCTION}

Genomic imprinting is an unusual epigenetic phenomenon in which the allele inherited from one parent is epigenetically silenced in the offspring and escapes Mendel's laws of heredity (Mannens and Alders, 1999). In mammals in particular, imprinted genes have an important function in the regulation of fetal growth, development, function of the placenta, and postnatal behavior (Isles and Holland, 2005; Zhang et al., 2007). Recently, an extensive comprehension of imprinted genes is becoming more and more important to animal breeders. However, most imprinted genes have been identified in humans and mice, and there are only a small number of imprinted genes identified in livestock (Lefebvre, 2012; Qiao et al., 2012). While there are extensive researches on imprinting in humans and mice, there is still a dearth of knowledge about imprinting in swine.

The Ras protein-specific guanine nucleotide-releasing factor 1 (Rasgrfl) is a $140-\mathrm{kD}$ protein that acts as a guanine-nucleotide exchange factor and activates the small g-proteins Ras and Rac in a calcium-dependent manner and forms part of the MAPK signaling pathway (Talebian et al., 2013). The mouse Rasgrf1 gene is located on chromosome 9 (De la Puente et al., 2002) and is predominantly expressed from the paternal allele in neonatal mouse brain, liver, heart, and stomach, with expression becoming biallelic during weaning and later into adulthood, whereas other tissues (e.g., lung, ovary, and testis) showed biallelic expression at all times (Plass et al., 1996; Charalambous et al., 2007; Dockery et al., 2009). The rat RasGrf1 gene is located on chromosome 8 and shows paternal-specific monoallelic expression in the neonatal brain (Pearsall et al., 1999). It was the first imprinted gene that was demonstrated to regulate postnatal rather than prenatal growth (Itier et al., 1998). Analysis of various knockout mouse strains uncovered a specific functional contribution of Rasgrfl in the processes of photoreception, control of postnatal growth, body size, and pancreatic $\beta$-cell function and glucose homeostasis (FernándezMedarde and Santos, 2011). However, no research on the imprinting status of the Rasgrfl gene has been carried out in swine (http://www.geneimprint.com; http://igc.otago.ac.nz).

In this study, we identified the imprinting status of Rasgrf1 in neonatal porcine tissues, utilizing the polymerase chain reaction/restriction fragment length polymorphism (PCR/ RFLP) method. To achieve our purpose, we subcloned the partial sequence of the domestic pig Rasgrf1 gene, identified a single nucleotide polymorphism (SNP) in Rasgrf1 exon 14, and analyzed its imprinting status in 14 organ/tissues of 1-day-old piglets. These results may be useful in marker-assisted and genomic selection breeding schemes. 


\section{MATERIAL AND METHODS}

All procedures involving animals were approved by the Animal Care and Use Committee of Anhui Agricultural University. All animals used in this study were derived from "the pig experimental station" of Anhui Agricultural University.

\section{Tissue samples and DNA preparation}

Ear tissues from an adult Berkshire pig and an adult Wannan black pig were obtained to search for SNPs. Genomic DNA was isolated from the white blood cells of sixteen 1-day-old F1 hybrid pigs ( 8 piglets of a Berkshire boar $\mathrm{x}$ Wannan black sow mating and 8 of a Wannan black boar x Berkshire sow mating) and their parents according to the standard phenol-chloroform method. Tissue samples (brain, heart, liver, spleen, lung, kidney, stomach, pancreas, fat, testis, ovary, small intestine, longissimus dorsi, and pituitary) from 7 heterozygous pigs (based on SNPs) of the 16 F1 hybrid pigs were collected for imprinting analysis.

\section{RNA isolation and cDNA synthesis}

Total RNA from all collected tissues was isolated with Trizol reagent (TaKaRa, Tokyo, Japan) according to the instructions of the manufacturer. First-strand complementary DNA (cDNA) was synthesized from $2 \mu \mathrm{g}$ total RNA treated with DNase I (TaKaRa) in a 20$\mu \mathrm{L}$ reaction volume containing $5 \mu \mathrm{M}$ oligo(dT)16 primer, $1 \mathrm{X}$ M-MLV first-strand buffer, 40 $\mathrm{U}$ M-MLV reverse transcriptase, $1 \mathrm{mM}$ of each dNTP, and $8 \mathrm{U}$ RNase inhibitor (TaKaRa) at $42^{\circ} \mathrm{C}$ for $60 \mathrm{~min}$.

\section{PCR of DNA and CDNA}

Highly conserved expressed sequence tags (ESTs) were obtained through standard Basic Local Alignment Search Tool analysis according to partial sequences of the human [National Center for Biotechnology Information (NCBI) Gene ID: 5923], mouse (NCBI Gene ID: 19417), and Sus scrofa (NCBI Gene ID: 100157221) Rasgrfl genes. Gene-specific primers for the Rasgrfl gene were designed using the highly conserved ESTs (Table 1).

\begin{tabular}{|c|c|c|c|}
\hline Method & Primer sequence $\left(5^{\prime}-3^{\prime}\right)$ & Annealing $\left({ }^{\circ} \mathrm{C}\right)$ & Product/size \\
\hline \multirow[t]{4}{*}{ PCR } & Exon 14 F: CCGACGCCTCCTTGTATTGT & \multirow[t]{2}{*}{62.4} & \multirow[t]{2}{*}{$\mathrm{DNA} / 228 \mathrm{bp}$} \\
\hline & Exon 14 R: TGGGCTTCCTGTAGATGGTGAT & & \\
\hline & Exon 1 F: GCGTGAGAAGGAGCGAGCCA & \multirow{2}{*}{64.0} & \multirow[t]{2}{*}{ DNA/193 bp } \\
\hline & Exon 1 R: TTGCGTGCCAGCAGTCCC & & \\
\hline \multirow[t]{2}{*}{ RT-PCR } & Exon $14 \mathrm{~F}^{\prime}$ : CCGACGCCTCCTTGTATTGT & \multirow[t]{2}{*}{63.0} & \multirow[t]{2}{*}{ cDNA/332 bp } \\
\hline & Exon 14 R': GTGGCTCGTGGGGACTTG & & \\
\hline
\end{tabular}

PCRs were performed in a $25-\mu \mathrm{L}$ volume containing $25 \mathrm{ng}$ porcine cDNA or $50 \mathrm{ng}$ DNA, 1X PCR buffer, $0.2 \mu \mathrm{M}$ of each primer, $150 \mu \mathrm{M}$ of each dNTP, $1.5 \mathrm{mM} \mathrm{MgCl}$, and 1 U Taq DNA polymerase (TaKaRa) using a Bio-Rad MyCycler PCR system (Bio-Rad, USA). 
The PCR conditions were as follows: $94^{\circ} \mathrm{C}$ for $4 \mathrm{~min} ; 32$ cycles of $94^{\circ} \mathrm{C}$ for $45 \mathrm{~s}$, annealing for $30 \mathrm{~s}$, and $72^{\circ} \mathrm{C}$ for $1 \mathrm{~min}$; and a final extension at $72^{\circ} \mathrm{C}$ for $10 \mathrm{~min}$.

\section{Sequencing and SNP detection}

PCR products were purified with the Wizard Prep PCR purification system (Promega, USA), cloned with the pMD18-T easy vector (TaKaRa), and sequenced commercially (Shanghai Sangon, China). To search for SNPs, sequences that were amplified by the primer pairs exon 14F/exon 14R and exon 1F/exon 1R in the Berkshire and Wannan black pigs were compared using the DNASTAR software (USA).

\section{RFLP of PCR and reverse transcription (RT)-PCR products}

Ten microliters of PCR or RT-PCR products (containing 0.1-1 $\mu \mathrm{g}$ DNA) amplified by the primer pair exon $14 \mathrm{~F} /$ exon $14 \mathrm{R}$ or exon $14 \mathrm{~F}^{\prime} /$ exon $14 \mathrm{R}^{\prime}$ was incubated at $37^{\circ} \mathrm{C}$ for $9 \mathrm{~h}$ with $3 \mathrm{U}$ of the restriction enzyme Vpak11AI (Thermo, USA) and $1 \mu \mathrm{L}$ attached $10 \mathrm{X}$ Vpak11AI Basal Buffer. Digested products were separated on 3\% agarose gels and stained with ethidium bromide.

\section{Imprinting analysis}

The RT-PCR/RFLP method was used to detect the imprinting status of the porcine Rasgrf1 gene. We chose the polymorphic locus g.84709 G>A and the restriction enzyme $V p a \mathrm{k} 11 \mathrm{AI}$ for imprinting analysis. The first step was screening for heterozygous piglets at the polymorphic locus g.84709 G>A. PCR was carried out on neonatal piglet and parental DNA using the primer pair exon 14F/exon 14R, and RT-PCR was performed on heterozygous piglet RNA using the primer pair exon 14F'/exon 14R', which were followed by Vpak11AI RFLP. By comparing the digestion patterns of the piglet's DNA/RNA and parental DNA, we could define the imprinting status of heterozygous piglets.

\section{RESULTS}

\section{Subcloning of the domestic pig Rasgrf1 gene}

In this study, we obtained 228- and 193-bp partial sequences of the domestic pig Rasgrfl gene. The two partial sequences are located in exon 14 and exon 1 of Rasgrfl, respectively. Sequence analysis showed that exon 14 of the domestic pig Rasgrfl gene had a high GC content (59.29\%), and the 228-bp sequence shared 93.4 and $83.9 \%$ nucleotide similarity with the human and mouse orthologs, respectively. Exon 1 of the domestic pig Rasgrfl gene had a high GC content (67.60\%), and the 193-bp sequence shared 91.2 and $79.3 \%$ nucleotide similarity with the human and mouse orthologs, respectively.

\section{SNP detection and screening for heterozygous piglets}

Comparison of the sequences from the Berkshire and Wannan black breeds revealed 
one SNP in exon 14 of the porcine Rasgrfl gene: the G-to-A SNP in exon 14 (NCBI Gene ID: 100157221 g.84709 $\mathrm{G}>\mathrm{A})$. The $\mathrm{SNP}\left(\mathrm{G} / \mathrm{A}^{84709}\right)$ in the coding region was a synonymous mutation and could be detected with the restriction enzyme Vpak11AI. Sixteen F1 piglets of the Berkshire $\mathrm{x}$ Wannan black cross were used to identify heterozygous individuals at the SNP site. Amplification of genomic DNA with the primer pair exon 14F/exon 14R was conducted. PCR products were digested by Vpak11AI. Allele g.84709G produced fragments that were 116, 75, and $38 \mathrm{bp}$, and allele g.84709A produced fragments that were 191 and 38 bp (Figure 1). Results of this PCR/RFLP test indicated that three Berkshire boar $\mathrm{x}$ Wannan black sow F1 hybrid piglets and four Wannan black boar x Berkshire sow F1 hybrid piglets were heterozygous at the site.

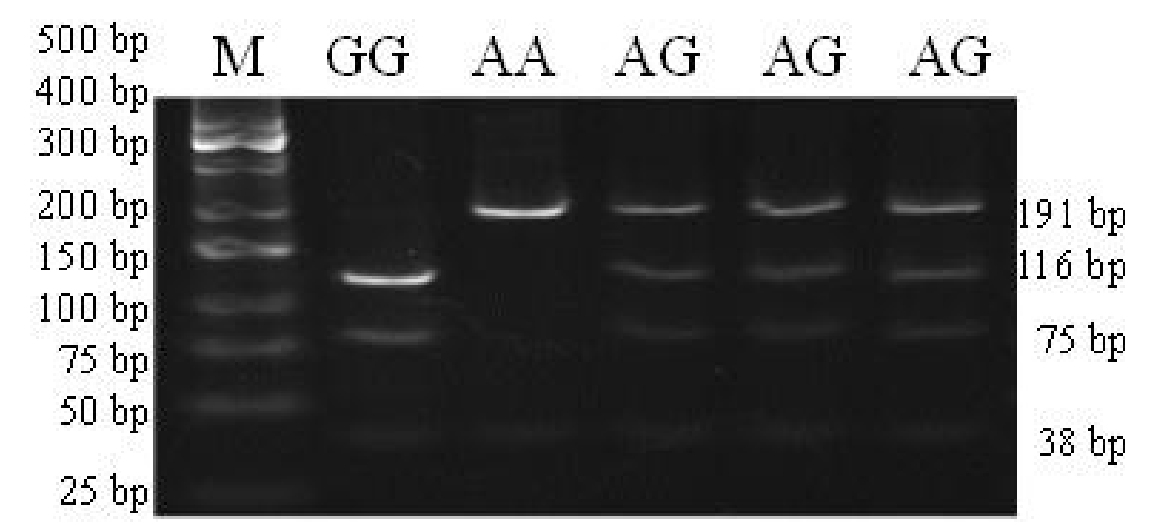

Figure 1. PCR-RFLP of the porcine Rasgrf1 gene. Lane $M=$ marker GM303 (the bands are 500, 400, 300, 200, 100 , and 75 bp from top to bottom, respectively; Sangon, Shanghai, China). Lanes $G G, A A$, and $A G=$ each of the different g.84709 G>A genotypes.

\section{Allelic expression of the porcine Rasgrf1 gene}

RT-PCR of the brain, heart, liver, spleen, lung, kidney, stomach, pancreas, fat, testis, ovary, small intestine, longissimus dorsi, and pituitary from the seven heterozygous piglets with the primer pair exon 14F'/exon 14R' showed that the porcine Rasgrfl gene was expressed in all of the tissues tested. Vpak11AI RFLP analysis of the RT-PCR products showed that the Rasgrfl gene was maternally expressed in the liver and small intestine, paternally expressed in the lung, and biallelically expressed in the brain, heart, spleen, kidney, stomach, pancreas, fat, testis, ovary, longissimus dorsi, and pituitary tissues. The g. $84709 \mathrm{G}$ allele was monoallelically expressed in the lung tissue, and the g.84709A allele was monoallelically expressed in the liver and small intestine tissues of three heterozygous Berkshire boar $\mathrm{x}$ Wannan black sow F1 hybrid piglets; the alleles originated from their Berkshire fathers and Wannan black mothers, respectively (Figure 2a). The g.84709A allele was monoallelically expressed in the lung tissue, and the $\mathrm{g} .84709 \mathrm{G}$ allele was monoallelically expressed in the liver and small intestine tissues of four heterozygous Wannan black boar x Berkshire sow F1 hybrid piglets; the alleles originated from their Wannan black fathers and Berkshire mothers, respectively (Figure 2b). 

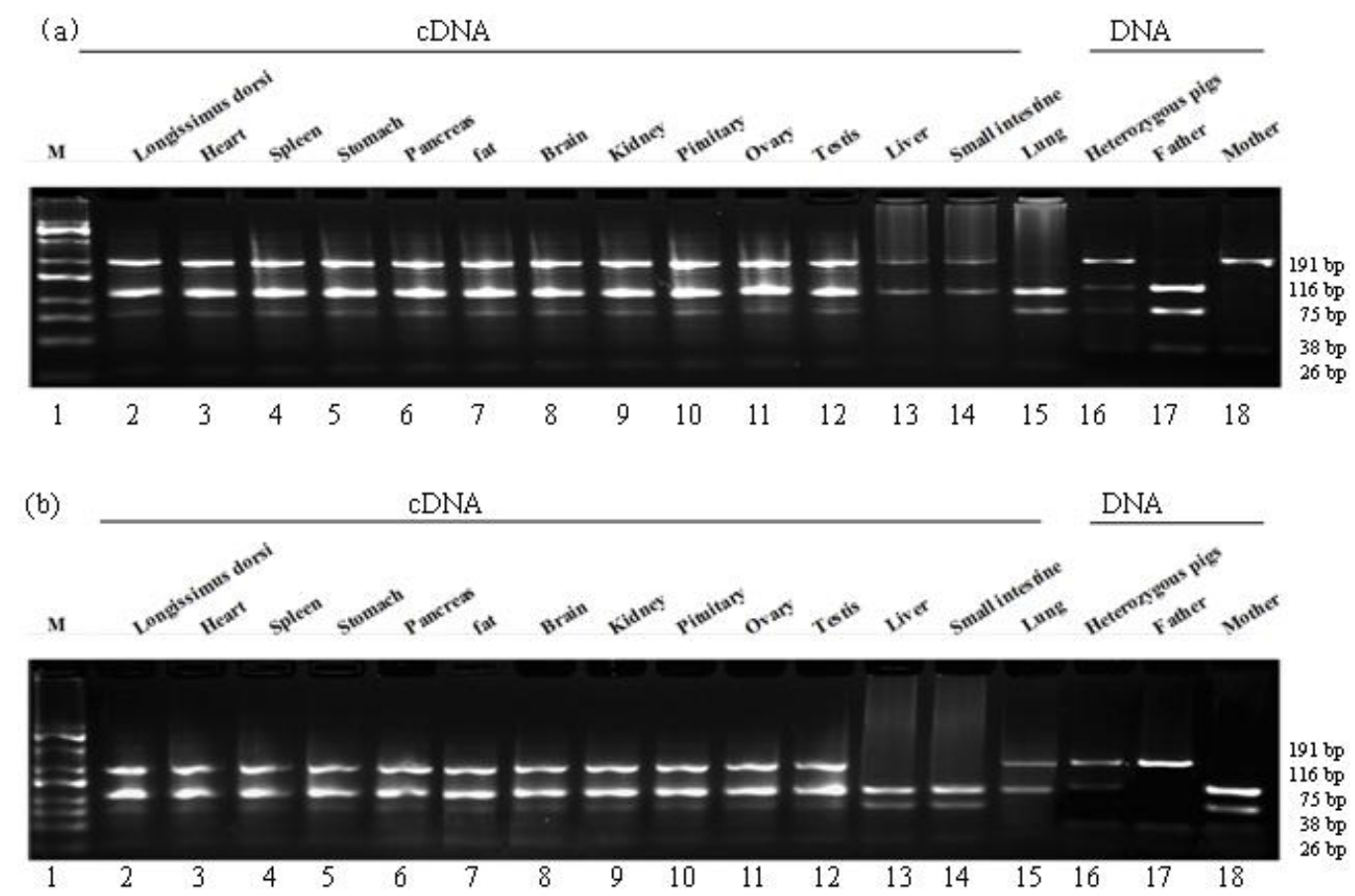

Figure 2. RT-PCR-RFLP/PCR-RFLP image of the allele-specific expression of the domestic pig Rasgrf1 gene. The complementary DNA (cDNA) samples are from 14 different tissues of a G-A heterozygous piglet (lanes 2 to 15), and genomic DNA samples are from the piglet, its father, and its mother (lanes 16, 17, and 18, respectively). Digestions with Vpak11AI revealed that the Rasgrfl gene is biallelically expressed in most of the tissues tested. The Rasgrf1 gene of Berkshire boar $\mathrm{x}$ Wannan black sow (a) and Wannan black boar x Berkshire sow (b) hybrid piglets are maternally expressed in the liver and small intestine (lanes 13 and 14), paternally expressed in the lung (lane 15). Lane 1 = marker GM303 (the bands are 500, 400, 300, 200, 100, and 75 bp from top to bottom, respectively).

\section{DISCUSSION}

In this study, a Berkshire $\mathrm{x}$ Wannan black F1 hybrid model and the RT-PCR/RFLP method were used to detect the imprinting status of the porcine Rasgrfl gene. Berkshire pigs are Western breeds, whereas Wannan black pigs are of Asiatic origin. These 2 breeds are genetically very different; therefore, it is easy to search for SNPs between Berkshire and Wannan black pigs, including SNPs in exons (Qiao et al., 2010). The frequency of heterozygous pigs, which was a prerequisite for imprinting analysis, was high in F1 hybrid pigs (Bischoff et al., 2009). Furthermore, we used the reciprocal F1 hybrids of Berkshire $\mathrm{x}$ Wannan black crosses to analyze the imprinting status of the porcine Rasgrfl gene. This model avoids the effect of gene expression in a single pig breed and makes the results reliable. The RT-PCR/RFLP method is rapid and convenient to detect the imprinting status compared with sequencing (Cheng et al., 2007). Therefore, the combination of the method and the model is convenient and believable for imprinting analysis.

It has been reported that the rat Rasgrf1 gene, located on chromosome 8, shows paternalspecific monoallelic expression in the neonatal brain (Pearsall et al., 1999). The mouse Rasgrf1, located on chromosome 9, is imprinted and exclusively expressed from the paternal allele in the 
neonatal brain, heart, stomach, and liver (Plass et al., 1996; Dockery et al., 2009). The imprinting of the mouse Rasgrf1 gene in a few tissues is relaxed during development, the transition from strongly and predominantly paternal allelic expression to biallelic expression can be seen over time, and expression becomes biallelic around the time of weaning (Drake et al., 2009). Interestingly, compared to the imprinted expression of the Rasgrfl gene in mouse and rat, we observed a variance in the imprinting of the Rasgrfl gene in domestic pigs. In our study, porcine Rasgrf1 was shown to have paternal-specific expression in the lung, maternal-specific expression in the liver and small intestine, and biallelic expression in other tissues (e.g., testis and ovary).

The imprinting status of the Rasgrfl gene has been elucidated in mouse and rat. However, this is the first investigation of the imprinting status of the Rasgrfl gene in swine. By first obtaining the partial exon 14 sequence, we found that, typical of imprinted genes (Amarger et al., 2002; Zhang et al., 2004), exon 14 of the porcine Rasgrfl gene was highly GC-rich. Furthermore, a de novo polymorphism located in exon 14 of the porcine Rasgrf1 gene was discovered and was presented for the first time here (http://www.ncbi.nlm.nih.gov/ SNP/snp_ref.cgi?locusId=100157221). The identification of an expressed SNP in the Rasgrf1 gene also allowed us to study its imprinting status by following the expression of the parental alleles in heterozygous pigs. We found that the Rasgrf1 gene was maternally expressed in the liver and small intestine, paternally expressed in the lung, and biallelically expressed in the brain, heart, spleen, kidney, stomach, pancreas, fat, testis, ovary, longissimus dorsi, and pituitary. These observations are not consistent with those from imprinting reports about the mouse and rat Rasgrfl gene (Plass et al., 1996; Dockery et al., 2009; Drake et al., 2009). The differential imprinting status of the Rasgrfl gene among rat, mouse and pig may be caused by the different species or the different tissues that were examined.

One of the limitations of this study is that no imprinting expression data at other porcine developmental stages, especially around weaning, was available to confirm the imprinting status of Rasgrf1. To identify the conservation of genomic imprinting at different developmental phases and in different species, the imprinting status of Rasgrfl around the time of weaning in pigs needs to be investigated in future studies.

In conclusion, this is the first study on the imprinting status of the Rasgrfl gene in domestic pigs. Our results showed that there is a general variation in the imprinting of the Rasgrf1 gene in species that have been studied so far, suggesting that the Rasgrfl gene shows both species- and tissue-specific variation in imprinted expression.

\section{Conflicts of interest}

The authors declare no conflict of interest.

\section{ACKNOWLEDGMENTS}

Research jointly supported by grants from the 2012 Expert Yard on Agricultural Science-Technology of Anhui Province (Grant \#20), the Transformation of Agriculture Scientific and Technological Achievements Foundation of China (Grant \#2012GB2C300207), the National Natural Science Foundation of China (Grants \#31171200 and \#30771581), the Anhui Provincial Science and Technology Department (Grant \#1301031032), the Natural Science Foundation of Anhui Province (Grant \#1208085MC44), and the Anhui Provincial Industrial Generic Technology Research Institute of Livestock and Poultry. 


\section{REFERENCES}

Amarger V, Nguyen M, Van Laere AS, Braunschweig M, et al. (2002). Comparative sequence analysis of the INSIGF2-H19 gene cluster in pigs. Mamm. Genome 13: 388-398.

Bischoff SR, Tsai S, Hardison N, Motsinger-Reif AA, et al. (2009). Characterization of conserved and nonconserved imprinted genes in swine. Biol. Reprod. 81: 906-920.

Charalambous M, da Rocha ST and Ferguson-Smith AC (2007). Genomic imprinting, growth control and the allocation of nutritional resources: consequences for postnatal life. Curr. Opin. Endocrinol. Diabetes Obes. 14: 3-12.

Cheng HC, Zhang FW, Deng CY, Jiang CD, et al. (2007). NNAT and DIRAS3 genes are paternally expressed in pigs. Genet. Sel. Evol. 39: 599-607.

De la Puente A, Hall J, Wu YZ, Leone G, et al. (2002). Structural characterization of Rasgrfl and a novel linked imprinted locus. Gene 291: 287-297.

Dockery L, Gerfen J, Harview C, Rahn-Lee C, et al. (2009). Differential methylation persists at the mouse Rasgrf1 DMR in tissues displaying monoallelic and biallelic expression. Epigenetics 4: 241-247.

Drake NM, Park YJ, Shirali AS, Cleland TA, et al. (2009). Imprint switch mutations at Rasgrf1 support conflict hypothesis of imprinting and define a growth control mechanism upstream of IGF1. Mamm. Genome 20: 654-663.

Fernández-Medarde A and Santos E (2011). The RasGrf family of mammalian guanine nucleotide exchange factors. Biochim. Biophys. Acta 1815: 170-188.

Isles AR and Holland AJ (2005). Imprinted genes and mother-offspring interactions. Early Hum. Dev. 81: 73-77.

Itier JM, Tremp GL, Léonard JF, Multon MC, et al. (1998). Imprinted gene in postnatal growth role. Nature 393: 125-126.

Lefebvre L (2012). The placental imprintome and imprinted gene function in the trophoblast glycogen cell lineage. Reprod. Biomed. Online 25: 44-57.

Mannens M and Alders M (1999). Genomic imprinting: concept and clinical consequences. Ann. Med. 31: 4-11.

Pearsall RS, Plass C, Romano MA, Garrick MD, et al. (1999). A direct repeat sequence at the Rasgrf1 locus and imprinted expression. Genomics 55: 194-201.

Plass C, Shibata H, Kalcheva I, Mullins L, et al. (1996). Identification of Grfl on mouse chromosome 9 as an imprinted gene by RLGS-M. Nat. Genet. 14: 106-109.

Qiao M, Wu HY, Li FE, Jiang SW, et al. (2010). Molecular characterization, expression profile and association analysis with carcass traits of porcine lcat gene. Mol. Biol. Rep. 37: 2227-2234.

Qiao M, Wu HY, Guo L, Mei SQ, et al. (2012). Imprinting analysis of porcine DIO3 gene in two fetal stages and association analysis with carcass and meat quality traits. Mol. Biol. Rep. 39: 2329-2335.

Talebian A, Robinson-Brookes K, MacDonald JI and Meakin SO (2013). Ras guanine nucleotide releasing factor 1 (RasGrf1) enhancement of Trk receptor-mediated neurite outgrowth requires activation of both H-Ras and Rac. $J$. Mol. Neurosci. 49: 38-51.

Zhang FW, Cheng HC, Jiang CD, Deng CY, et al. (2007). Imprinted status of pleomorphic adenoma gene-like I and paternal expression gene 10 genes in pigs. J. Anim. Sci. 85: 886-890.

Zhang S, Kubota C, Yang L, Zhang Y, et al. (2004). Genomic imprinting of $H 19$ in naturally reproduced and cloned cattle. Biol. Reprod. 71: 1540-1544. 